\title{
Knowledge mapping analysis of CHD research in Web of Science Youliang Huang ${ }^{1, a,{ }^{*},}$ Sajid Ali ${ }^{2, b}$, Xingguang Ma1 ${ }^{1}$, Fengying Guo ${ }^{1}$, Li Wang ${ }^{1}$ and Renquan Liu ${ }^{1}$

\author{
${ }^{1}$ Information center, Beijing University of Chinese Medicine, Beijing, China \\ ahuangyl@bucm.edu.cn *Corresponding author : Youliang Huang
} \\ ${ }^{2}$ Department of Computer Science, University of Education,Lahore, Pakistan
}

Keywords: Coronary heart disease, Knowledge mapping, Research paper, Web of Science

\begin{abstract}
Based on web of science retrieval tools, bibliometric analysis published on the world through the research field of 2007-2017 years of the coronary heart disease, combined with CiteSpace and Excel analyze the development of coronary heart disease in the research field of Excel software, the research status (including research methods, basic theoretical research and applied research, etc.) and the future development trend, key areas summarize the research of coronary heart disease, and puts forward some suggestions on the future research focus.
\end{abstract}

\section{Introduction}

Coronary heart disease is the abbreviation of coronary heart disease, is one of the most common heart disease, refers to coronary artery stenosis, insufficient blood supply caused by myocardial dysfunction and / or organic lesions, it is also called ischemic cardiomyopathy. Coronary heart disease (CHD) is a heart disease characterized by myocardial ischemia, hypoxia (angina pectoris) or myocardial necrosis (myocardial infarction) caused by stenosis or obstruction of the coronary arteries (or atherosclerotic or dynamic vasospasm), also called ischemic heart disease $[1,2]$. The occurrence of coronary heart disease is closely related to the degree and number of coronary atherosclerotic stenosis, while hypertension, diabetes and other diseases, as well as excessive obesity, bad habits, etc. are the main factors inducing the disease. Coronary heart disease is one of the deadly diseases in the world. According to the WHO report in 2011, the number of coronary heart disease deaths in China has been ranked second in the world.

\section{Literature sources and research methods}

In this paper, "coronary heart disease" as the theme, with web of science as search source, retrieval time is 2007-2017, a total of 47689 literatures related to coronary heart disease; remove the notice of meeting documents, a total of 37,139 articles on the knowledge map of literature, some of which are on their coronary heart disease theory, some research on the method of treating coronary heart disease. Some applied research on the pathogenesis of coronary heart disease gene. By using the bibliometric analysis method of characteristics in the literature for statistical analysis, including data to describe the growth law, periodicals distribution, subject distribution; then on the basis of quantitative analysis, analysis of the literature content were analyzed and summarized by literature qualitative, reveal the present research status of coronary heart disease research.

\section{Literature sources and research methods}

\subsection{Analysis of published papers}

The quantity of papers and the trend of the times can reflect the current situation of a certain study in a specific period of time. The data of Figure 1 showed that the number of coronary heart disease research papers showed an overall upward trend from 2012 to 2017 . When retrieving the web of science data, this paper includes the 2017 paper, which was published in 2017 October, because the time lag of the papers included in the database was so late that the paper was published in 2017. 
According to the law of quantity and trend of Figure 1, we believe that 2018 will be the peak year of coronary heart disease research. According to the trend of L, we believe that coronary heart disease research is still a hot topic in the field of chronic disease research in the next few years.

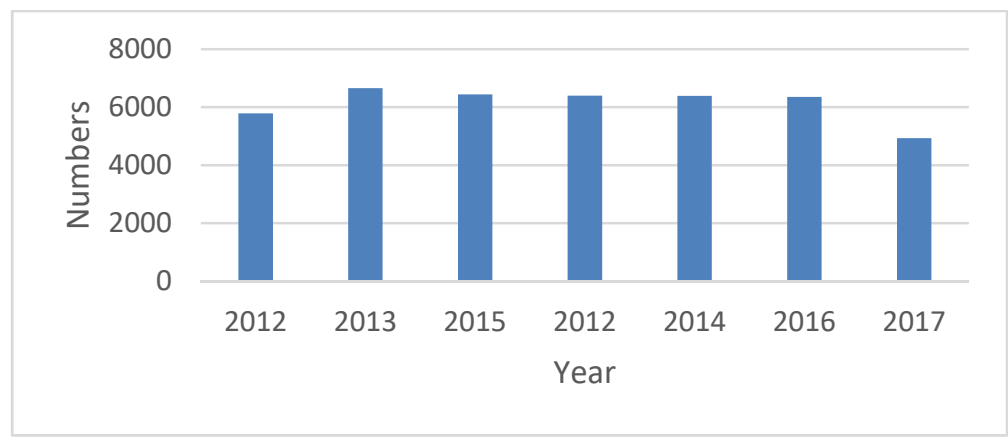

Fig. 1. Distribution of research papers

\subsection{Periodical distribution}

The analysis of journal articles can reflect the subject orientation of this field to a large extent. In this study, we only consider the quantity of the journal, and don't consider the time and frequency of publication. 37,139 papers were distributed in more than 100 journals. Table $\mathrm{L}$ is the top 10 Journal of the volume of publications.

Table 1. Journal distribution table

\begin{tabular}{cc}
\hline Journal & Number \\
\hline PLOS ONE & 1497 \\
\hline INTERNATIONAL JOURNAL OF CARDIOLOGY & 805 \\
\hline ATHEROSCLEROSIS & 645 \\
\hline AMERICAN JOURNAL OF CARDIOLOGY & 638 \\
\hline JOURNAL OF THE AMERICAN HEART ASSOCIATION & 434 \\
\hline CIRCULATION & 429 \\
\hline JOURNAL OF THE AMERICAN COLLEGE OF CARDIOLOGY & 379 \\
\hline
\end{tabular}

PLOS ONE, INTERNATIONAL JOURNAL OF CARDIOLOGY and ATHEROSCLEROSIS published the most articles in the three journals, which indicated that the quality of papers on coronary heart disease was higher.

\subsection{Author analysis}

Through the CiteSpace software 37,139 articles were retrieved The statistical analysis of the article selects the top 10 of the number of entries The author draws a chart of the quantity of papers published by the author.

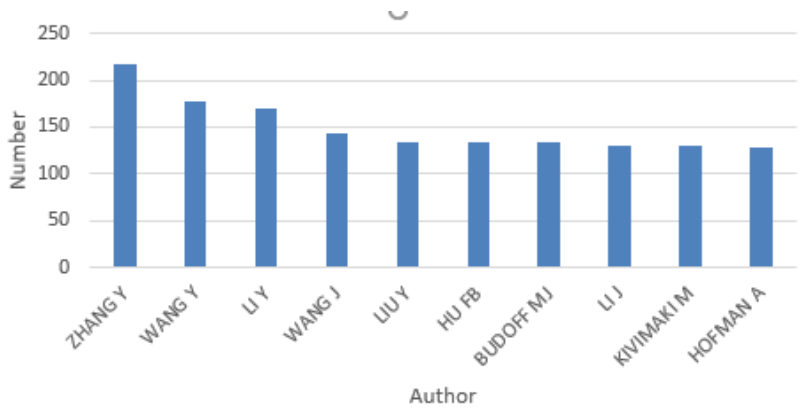

Fig. 2. Distribution of author

\subsection{Research institutions analysis}

The number of research institutions shows that the research team of coronary heart disease is relatively concentrated, mainly concentrated in Harvard University, Brigham Womens Hosp, Univ Washington, Johns Hopkins Univ, Mayo Clin and other institutions of higher learning or scientific 
research institutions. Universities and hospitals are the main institutions for coronary heart disease research. The Figure 1 shows the research institutions analysis.

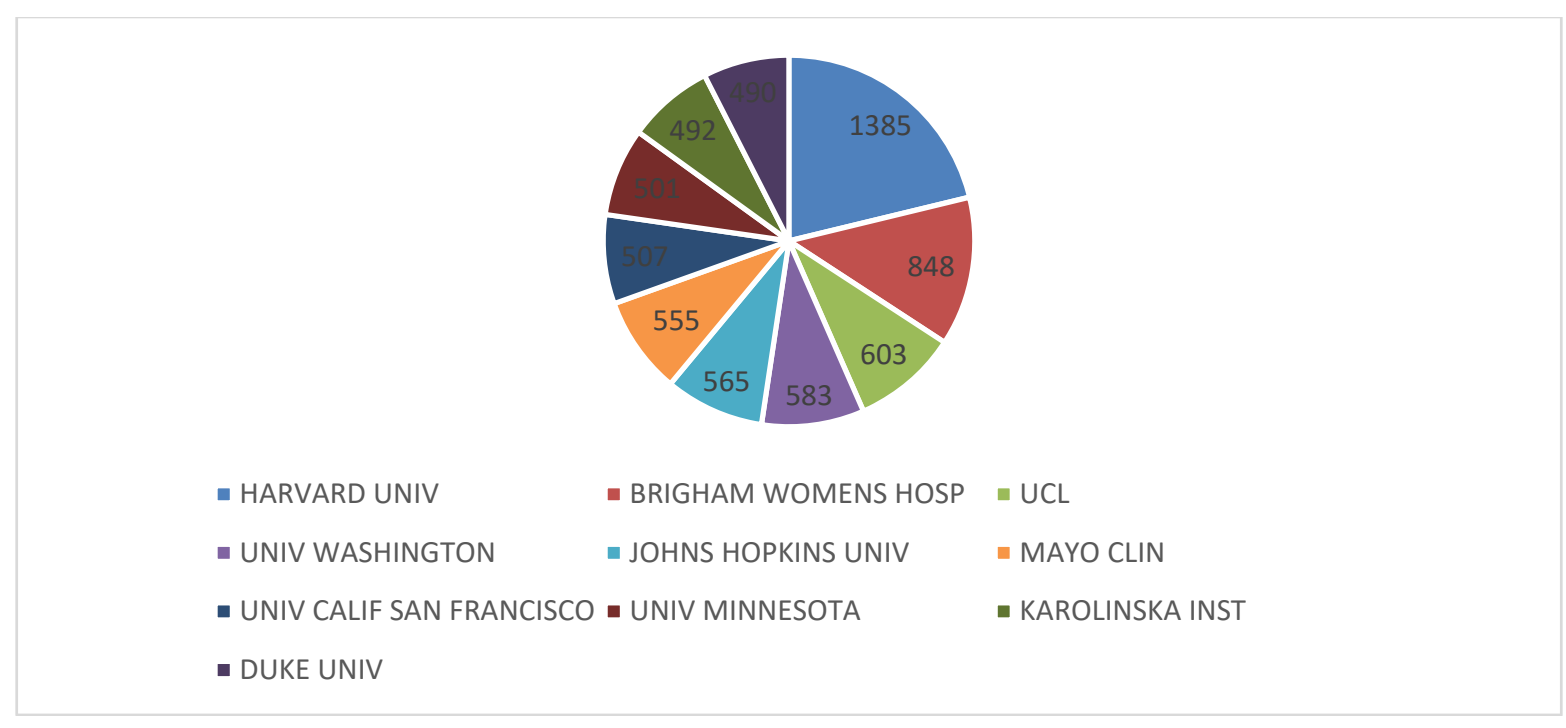

Fig. 3. the research institutions analysis

\subsection{Funding institutions}

The study of coronary heart disease has been funded by different types of funding, and it is the funding of these projects that has contributed to the deepening of coronary heart disease research. The top 10 are shown in table 2.

Table 2. Funding institutions

\begin{tabular}{cc}
\hline Institutions & Number \\
\hline NATIONAL NATURAL SCIENCE FOUNDATION OF CHINA & 1189 \\
\hline NATIONAL INSTITUTES OF HEALTH & 1151 \\
\hline NATIONAL HEART LUNG AND BLOOD INSTITUTE & 1023 \\
\hline NIH & 728 \\
\hline ASTRAZENECA & 554 \\
\hline BRITISH HEART FOUNDATION & 538 \\
\hline PFIZER & 522 \\
\hline AMERICAN HEART ASSOCIATION & 408 \\
\hline
\end{tabular}

\subsection{Research direction analysis}

The topic analysis of the paper can reflect the focus and focus of the research field to a certain extent, which is helpful to understand its current research status and level, and help researchers correctly predict the development trend and direction of the field [3], so as to make the research more targeted and more valuable. The figure 4 shows the research direction analysis. 


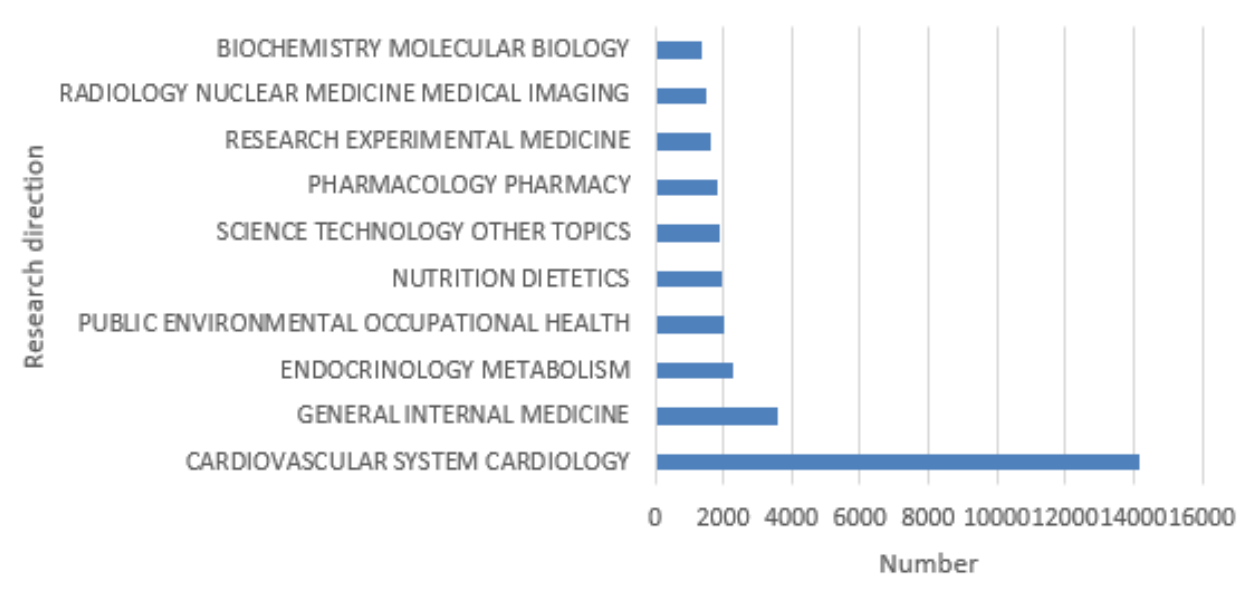

Fig. 4. the research direction analysis

\section{Summary}

The application of CiteSpace and Excel software to draw the knowledge of coronary heart disease, is displayed in recent 5 years web of research hotspot and Frontier Literature of coronary heart disease in the science database, shows the scientific research team and its development in the field of the world more influential in coronary heart disease $[4,5]$. Through the analysis of the knowledge map of coronary heart disease, it is found that in the field of coronary heart disease research, the theory and technology of traditional Chinese medicine are more in-depth.

\section{Acknowledgement}

The authors are very grateful to the referees and anonymous reviewers for their helpful comments and suggestions. This work was supported, in part, by Beijing University of Chinese Medicine (Grant No. 2016-JYB-QNJSZX005) and Beijing University of Chinese Medicine (Grant No. 2016-JYBLSMS-019).

\section{References}

[1] Cohen L S, Coronary heart disease, American Journal of Cardiology, vol.17, pp. 153-168, 1966.

[2] Heran B S , Exercise-based cardiac rehabilitation for coronary heart disease, Journal of the American College of Cardiology, vol.67, pp. 1-11, 2016.

[3] Ding X, Getting started in text mining to find the biological network shared with rheumatoid arthritis, coronary heart disease and diabetes mellitus, European Journal of Operational Research, vol.185, pp. 726-742, 2008.

[4] Pradhan A D, Inflammatory biomarkers, hormone replacement therapy, and incident coronary heart disease: prospective analysis from the Women's Health Initiative observational study, Acc Current Journal Review, vol. 12, pp. 28-28, 2002.

[5] Sr, D. R , A Validation of the framingham coronary heart disease prediction scores: results of a multiple ethnic groups investigation, Jama the Journal of the American Medical Association, vol. 286, pp. 1-10, 2001. 